\title{
Correction to: Sustainable Approaches for Biofuels Production Technologies
}

Neha Srivastava, Manish Srivastava, P. K. Mishra, S. N. Upadhyay, Pramod W. Ramteke and Vijai Kumar Gupta

\section{Correction to:}

N. Srivastava et al. (eds.), Sustainable Approaches

for Biofuels Production Technologies, Biofuel and Biorefinery Technologies 7, https://doi.org/10.1007/978-3-319-94797-6

In the original version of the book, the following belated correction has been incorporated: The editor name has been changed from "Vijaj Kumar Gupta" to "Vijai Kumar Gupta" on the cover and in the front matter. 